DOI 10.37882/2500-3682.2020.11.21

\title{
К ПРОБЛЕМЕ СТАНОВЛЕНИЯ СОЦИАЛЬНОЙ ФИЛОСОФИИ ХХ ВЕКА: КОНКРЕТИЗАЦИЯ МАРКСОМ КОНЦЕПЦИИ ОТЧУЖДЕНИЯ
}

\section{TO THE PROBLEM OF THE FORMATION OF SOCIAL PHILOSOPHY OF THE XX CENTURY: MARX'S CONCEPTING THE CONCEPT OF ALIENATION}

\section{A. Ogarkov \\ L. Smetankina}

Summary: In this article, the author examined the issues of the formation of social philosophy of the 20th century. Particular attention in the article was paid to the consideration of the point of view of K. Marx regarding this issue and the concept of "alienation".

K. Marks in his works overturned the traditional narrow understanding of political economy as the science of the general conditions of production and consumption, consistently isolating and separating the normative meaning of categories and their actual historical content.

Keywords: social philosophy, the concept of alienation, Karl Marks, political economy, the concept of social wealth.
Огарков Александр Николаевич

К.ф.н., дочент, ФГБОУ ВО «Санкт-Петербургская государственная художественно-промышленная академия имени А. Л. Штиглица» suer53@inbox.ru

Сметанкина Людмила Васильевна

д.ф.н., nрофрессор, ФГКВОУ ВО «Военная академия связи имени Маршала Советского Союза С. М. Буденного» МО РФ

Ismetankina.umo@mail.ru

Аннотация: В данной статье автором были рассмотрены вопросы становления социальной философии 20 века. Особое внимание в статье было уделено рассмотрению точки зрения К. Маркса относительно данного вопроса и концепции «отчуждения».

К. Маркс в своих работах перевернул традиционное узкое понимание политэкономии как науки об общих условиях производства и потребления, последовательно вычленяя и отделяя нормативное значение категорий и их действительное историческое содержание.

Ключевые слова: социальная философия, концепция отчуждения, Карл Маркс, политэкономия, концепция общественного богатства.

Методологическая трудность состоит здесь в том, что редукция нормативного значения категорий буржуазной политэкономии и социологии (как научный прием) не отделяется Марксом от поиска новых средств уточнения принятой им в варианте рабочей гипотезы пока еще абстрактной модели прогресса и общей корреляции частей общественной целостности. И архитектоника рукописи, и разброс понятий, различающихся предметно и содержательно, и их общий гуманистический пафос - признаки радикального изменения требований к прогрессу, к идеалу будущего общественного устройства, к субъекту истории; - требований, которые должны быть обоснованы уже нетрадиционным путем.

На данном этапе формирования материалистической концепции истории новация Маркса состоит в полном переосмыслении представлений об общественном богатстве, в отбрасывании буржуазных интерпретаций и фетишизации труда, представлений о причинах и последствиях промышленного развития. Работа представляет собой единство трех логических «блоков», связь которых выявляется и как философская дедукция, и как изолированное в каждой части, но имеющее одно основание и один предмет, доказательство. Условно эти части могут быть обозначены: «политэкономия и отчуждение»; «отчуждение и коммунизм»; «единство гегелевской философии и буржуазной политэкономии как моментов отчуждения». Изменение удельного веса узко-фило- 
софского аспекта критики в рукописях свидетельствует о смещении центра исследований непосредственно в сферу анализа буржуазных общественных отношений, их создания человеком и их влияния на человека. В первой части рукописи Маркс подвергает анализу три категории буржуазной политэкономии, фиксирующие общественное положение трех основных классов буржуазного общества и три вида доходов - капитал, земельную ренту и заработную плату.

Современная Марксу политэкономия была единственной областью гуманитарного знания, в которой достаточно точно моделировались общественные отношения как отношения по распределению средств производства и общественного богатства. Политэкономия не могла не быть исторической наукой (в теперешнем ее понимании Марксом), не могла не отражать идеологических ценностей класса (в превращенной форме концепции общественного богатства). Поэтому анализ политэкономических учений является для Маркса выявлением антигуманистической сущности общественных отношений в различных ее проявлениях (управление и подчинение, отношение капиталистического владения как правовое отношение, концентрация жизненных средств одних людей в руках других). Капиталистическое отношение прежде всего кристаллизуется в праве: «Как человек становится собственником продуктов, производимых с помощью производительных фондов? На основании положительного права». Маркс резюмирует: «Итак, капитал есть командная власть над трудом и его продуктами. Капиталист обладает этой властью не благодаря своим личным или человеческим свойствам, а лишь как собственник капитала» [6, с. 59]. Здесь сказывается остаточное влияние на Маркса и концепции естественного права Ж.-Ж. Руссо (узурпация и последующее извращение в истории естественных прав тружеников и навязывание этого извращенного права как неизменного отношения) [7].

Маркс цитатами из Милля, Сэя, В. Шульца обосновывает тезис о фактическом уничтожении в условиях буржуазного производства всего человеческого в создателе предметного мира - рабочем. Закрепленное в праве общественное положение капиталиста как собственника всех условий производства обеспечивает ему минимальный доход в условиях самой неблагоприятной конъюнктуры; положение же рабочего и сама его жизнь определяются размерами заработной платы, приравниваемой, как правило, к стоимости средств для поддержания его существования. Земельная рента является одной из исторических форм капитала в развитии капиталистического производства к адекватной форме - фабричной системе. Земельный собственник превращается в капиталиста, капиталистическое отношение окончательно кристаллизуется как отношение капиталиста и рабочего. Это отношение - исторический результат отчуждения рабочим своих жизненных сил и присвоения их капиталистом факт, скрываемый буржуазной политэкономией.

Таким образом, вскрытая Марксом в 1843 году связь частной собственности и государства уточняется. Связь эта сама является порождением первичной связи рабочего с формой его существования и жизнедеятельности - с трудом, а также его результатами. История демонстрирует многообразие форм проявления и закрепления этой связи, как связи рабочего с порождаемыми им в труде, враждебными ему формами. Теоретический центр исследования - выход Маркса в анализе им отчужденного труда за рамки буржуазных концепций общественного богатства.

Речь идет о труде как важнейшем родовом признаке человека; осуществление труда в буржуазном обществе есть процесс уничтожения его агента - рабочего. Труд, опредмечиваясь, деперсонифицируется и рождает капитал, безразличный к предметному содержанию труда. В обезличенном труде исчезают родовые человеческие связи. Однако в самих рукописях эта первоначальная трактовка родовых признаков человека в последующем изменяется: «Рассмотрение разделения труда и обмена представляет величайший интерес, потому что это наглядно отчужденные результаты человеческой деятельности, как родовой деятельности, и человеческой сущностной силы как родовой сущностной силы» [6, с.144]. Изменяется также данная в первой рукописи чисто негативная оценка промышленности как исторической формы отчуждения. Первоначально трактуемая как чистая негативность, частная собственность к концу рукописей понимается уже как момент истории: «... Человеческая жизнь нуждалась для своего осуществления в частной собственности. Теперь она нуждается в упразднении частной собственности» [6, с.144]. Концепция отчуждения в «Экономическо-философских рукописях» является одним из нескольких инструментов для выявления специфики капиталистических отношений. Маркс в первой рукописи отмечает, что из понятия отчужденного труда путем анализа можно получить не только понятие частной собственности, но и все экономические категории, определенное и развернутое выражение этих первых основ. В ходе исследования отношений частной собственности как превращенных форм труда выясняется, что термин «отчуждение» трактуется им более широко, чем Фейербахом и Гессом. В рукописях могут быть вычленены те логические переходы, которые связаны с интерпретацией отчуждения и тем, и другим. В первой рукописи после отмеченной Марксом методологической ограниченности буржуазной политэкономии, представитель которой «предполагает в форме факта, события то, что он должен дедуцировать» [6, с.87], следует анализ отчужденного труда. Отчуждение рассматривается в рукописях:

1. как отношения рабочего к условиям труда (внешнее отчуждение); 
2. как отношение, возникающее в самом трудовом процессе;

3. как отрыв рабочего от природных связей, уничтожение его родовой сущности;

4. как двоякое отношение воспроизводства отчуждения: «Посредством отчуждения труда человек порождает не только свое отношение к предмету и акту производства, как к чуждым и враждебным ему силам, он порождает также и то отношение, в котором другие люди находятся к его производству и к его продукту, а равно и то отношение, в котором сам он находится к этим другим людям» [6, с. 96];

5. как враждебность порожденной буржуазным обществом квинтэссенции богатства - денег - всем формам их непосредственной реализации для потребления, враждебность возможности наслаждаться всеми конкретными видами наслаждения. С другой стороны - отсутствие меры в потреблении (бесконечное утончение форм потребления).

Сложившаяся традиция в употреблении термина «отчуждение», использование его Фихте, Гегелем, Фейербахом, младогегельянцами, широкий спектр значений - все это привело к необходимости замещения этого понятия более адекватными формирующимся представлениям об историческом процессе. Но понятие это Маркс продолжал использовать, в частности, в «Капитале». В «Экономическо-философских рукописях» Маркс вновь обращается к гегелевской философии. Симптоматично, что за основу критики на этот раз берется уже метод конструирования противоречий в «Феноменологии духа» как метод полагания, снятия и последующего восстановления отчуждения: отчуждение у Гегеля представляет интерес само по себе, как снятие образования отчуждения. Все другие противоположности - видимости этих интересных противоположностей, которые образуют смысл других, вульгарных противоположностей. Философия Гегеля не случайно рассматривается в рукописях после работ буржуазных политэкономов. Абстрактно-всеобщий характер духовной деятельности у Гегеля, обезличенный характер труда у Рикардо - лишь различные аспекты одного и того же общественного состояния - бесчеловечности. У Гегеля это нашло выражение в замкнутой связи понятий, отрицание которых друг другом есть восстановление состояния отчуждения от реального мира при видимости полного усвоения его содержания.

Но Гегель своим методом схватил сущность труда и встал на точку зрения политэкономии. «...В гегелевской философии права снятое частное право равняется морали, снятая мораль равняется семье, снятая семья равняется гражданскому обществу, снятое гражданское общество равняется государству, снятое государство равняется всемирной истории. В реальной действительности частное право, мораль, семья, гражданское общество, государство и т.д. продолжают существовать по-прежнему, они только стали моментами, формами существования и наличного бытия человека, которые не имеют силы изолироваться друг от друга, отменять друг друга, порождать друг друга и т.д.» [6, с.167]. В чем же сущность действительного движения в истории и адекватного этой действительности ее описания? Здесь Маркс вновь, как и в начале своей теоретической деятельности, разрешает проблему разумно понятой действительности, и ее моделирования в системе гуманитарного знания. История - всегда фиксация процесса в его стадиях, и в его настоящем виде. Такой историей, по Марксу, должна стать история промышленности, как история реализации сущностных сил человечества и его самого: образование пяти внешних чувств - это работа всей предшествующей истории» [6, с.122]. В обыкновенной промышленности мы видим опредмеченные сущностные силы человека. Такая психология, для которой эта книга, то есть как чувственно наиболее осязательная, наиболее доступная часть истории, закрыта, не может стать действительно содержательной и реальной наукой» [6, с.123].

С подобной трактовкой исторического метода мы сталкиваемся уже далее - в «Немецкой идеологии». Вычленяя различные формы идеологического фетишизма капиталистических отношений, Маркс намечает возможности перехода к новой ценностной модели, в которую не только включен человек, как создатель товарного мира, но и сама промышленность рассматривается как «экзотерическое раскрытие человеческих сущностных сил» [6, с.124]. Намечается новая связь естествознания и гуманитарного знания, когда естествознание «станет основой человеческой науки, подобно тому, как оно уже теперь - хотя и в отчужденной форме - стало основой действительной человеческой жизни, а принимать одну основу для жизни, другую для науки - это значит, с самого начала допускать ложь» [6, с. 124]. Необходимо создать новый исторический метод и новую историю, для которой буржуазное общество не являлось бы точкой отсчета, и которая в общих чертах дала бы описание будущего общества.

Маркс впервые здесь называет это будущее состояние «коммунизмом», причем коммунизмом, начинающимся с частной собственности. Маркс в самом начале формирующейся концепции будущего общества был далек от современных ему утопий и рассматривает коммунизм здесь уже не как конструкцию, а как результат процесса. В рукописях отвергаются положения грубого, уравнительного коммунизма, для которого идеалом выступает коллективная собственность, которая уничтожает то, чем не обладают все, следовательно, отрицает личность: человека и является последовательным выражением частной собственности, низводящей работника до «неестественной простоты», бедного, грубого и не имеющего потребностей человека. В этом пункте Маркс выходит за пределы концепции естественного 
права. Первичное состояние общества до возникновения форм частной собственности возвратить невозможно, так как уже существует тип человека, сформированный промышленным развитием, а коммунизм как положительное упразднение (то есть просто отбрасывание частной собственности) стал бы только новой формой само-отчуждения человека: коммунизм, мыслящий себя как реинтеграция, то есть возвращение человека к человеку, но не уяснив положительной сущности частной собственности и не постигнув человеческой природы потребности, тоже находится в плену у частной собственности. Таким образом, на первом этапе формирования теории социализма Маркс уже использует те аргументы в рассуждении о поэтапном движении к коммунизму, которыми он пользовался в поздний период, в частности, в работе «Критика Готской программы». Итак, В «Экономическо-философских рукописях» фиксируется единство буржуазных форм знания как идеологических форм, враждебных человеку; закладываются основы нового исторического метода; намечаются общие черты будущего коммунистического устройства общества; проблема отчуждения позитивно интерпретируется как проблема будущего освобождения труженика возвращением к такому общественному состоянию, когда им присваивается и труд, и результаты труда. Делается вывод о том, что сферой родовой жизни человечества является производство. История интерпретируется как процесс движения родовой сущности в направлении ее адекватной реализации, причем буржуазное общество представляется моментом деформации общей схемы человеческого движения к этой реализации. Схема прогресса обогащается анализом факторов человеческой деятельности как производства жизни. Формируются новые представления об исторических циклах и общественной целостности. В «Экономическо-философских рукописях» формируется идея большого исторического цикла (эпоха равенства тружеников - эпоха отчуждения труда - эпоха свободы производителя), и конкретизируется схема детерминации сфер общественного целого (производство - гражданское общество - государство).

Следующий этап интеграции элементов социальнофилософского знания в марксистскую системную модель общественного развития - конкретизация Марксом и Энгельсом модели общественного прогресса в «Немецкой идеологии». «Гражданское общество» уже не только «фиксация» области действительных отношений граждан в противовес их отчужденным отношениям, фиксируемым в понятии «государство», а исторически определенная социальная структура. «Немецкая идеология» строится как аналитическое историческое исследование, в начале которого формулируются материалистические предпосылки нового исторического метода. Условия человеческого существования - вот те простейшие элементы, на которых строится все структурное многообразие истории. Сфера действительных, исторических отношений - сфера производства и воспроизводства человеческой жизни.

В этом пункте новый исторический метод есть метод политэкономии как реконструированной науки. Использование политэкономического категориального аппарата позволяет приблизиться к идеалу научности возможность сопоставить следствие гипотезы с конкретными фактами: «Там, где прекращается спекулятивное мышление, перед лицом действительной жизни, там как раз и начинается действительная положительная наука, изображение практической деятельности, практического процесса развития людей» [8, с. 26]. Сведение всего бесконечного феноменологического многообразия истории к ее основаниям позволило осуществить координацию отдельных областей гуманитарного знания путем соотнесения их выводов с выводами науки об условиях производства и потребления, обогащенной генетическим анализом этих условий как элементов системы производства.

Таким образом, исторически понятая политэкономия становится действительной историей, а привлечение всего богатства форм описания условий жизни общества позволяют вычленить особенное в историческом процессе. История понимается как производство жизни, а фиксация изменения способов этого производства возможна лишь в категориях не спекулятивной, в данном случае сводимой к проверяемым фактам, теории. В процессе воспроизводства человеком себя и всех условий своей жизни возникает общение как способ производства и общность как совокупность всех форм общения (социальное целое). Собственно предмет философии в его традиционном понимании является в этой работе больше предметом рассмотрения. Философия рассматривается в «Немецкой идеологии» как метод сведения всех направлений гуманитарного знания к эмпирической «данности». Фрагменты гуманитарного знания, соотнесенные с единым основанием, приобретают новое качество - способность объяснять, поскольку всегда обнаруживается причинно-следственная зависимость, единая для всех модификаций гуманитарного знания. Таким образом, общество, понимаемое как эмпирическая "данность», определяет и строение социальнофилософского знания. Маркс и Энгельс добиваются концептуального единства моделей функционирования и развития. В дальнейшем, по мере освоения эмпирического материала, эта модель усложняется, уточняются методологические границы основных категорий, соответствующих усложненной модели прогресса.

История природы и история общества совпадают, это один процесс изменения человеком собственной природы в предметной деятельности. Какова же связь моментов непрерывности и прерывности в историческом развитии? Производство непрерывно, поскольку 
непрерывно человеческое существование. Неизменны и общие условия производства жизни, одинаковые для всех эпох. Но эти общие условия должны быть основанием для анализа отдельных исторических эпох, именно в этом случае возможно историческое объяснение. Специфика истории в разнообразии форм частной собственности, в различии форм отделения ее от общности (G e m e i n w e s e n), в специфике корреляции данной формы частной собственности с типом государственного управления, в широком смысле - с идеологией как одной из форм отчуждения.

Непрерывность истории выявляется фиксацией неизменности ее материальной основы, но способ общения определяет исторический цикл. В «Немецкой идеологии» очевиден переход Маркса от общей типологии исторических форм как готовых форм права к более сложной классификации. Усложняются представления о корреляции сфер общественной целостности. Выведен новый ряд детерминации (отношения производство - идеология). Но это - лишь толчок к дальнейшему углублению анализа. Начиная с «Экономическо-философских рукописей 1844 года» Маркс упорно возвращается к описанию исторических условий, благодаря которым возникает способ производства, к определению границ исторического пространства, в котором кристаллизуется форма общения. Это ясно сформулированный принцип познания социальных явлений: когда принадлежность общественной целостности к типу определяется конкретным историческим, а не поверхностным сравнительным анализом. Развитие социальной философии марксизма - встречное движение формирующейся социологической схемы с выводами аналитико-исторической реконструкции. В «Немецкой идеологии» отмечаются исторические условия, тормозящие или ускоряющие процесс отделения частной собственности от общины. Например, в эпоху Римской республики концентрация частной собственности и превращение мелких крестьян в пролетариат не получило массового распространения. Но разрушение империи привело к захвату ее провинции германскими племенами, что способствовало освоению этими племенами новых земледельческих орудий труда, ускоряло процессы формирования нового типа владения в условиях ослабления централизации власти. Это уже историческое описание, имеющее исходным пунктом социологическую гипотезу. Осуществляется как бы обратное теоретическому, повторяющее естественное, движение. Каждый этап выявления связи политэкономических категорий - определенная стадия исторического движения. Все зачатки современной Марксу промышленной систе- мы существовали, по его замечанию, еще в античности. Но именно в условиях средневековой Европы связь первичных форм собственности и капиталистической была опосредована целым рядом ступеней, что и способствовало формированию классической капиталистической формы собственности. История, понятая как связь этапов разделения труда и соответствующих им типов общения, эксплуатации, развертывается именно в средневековой Германии. Таким образом, в основе нового исторического метода лежит тезис о том, что условия производства и общения образуют исторический ряд форм общения. Развиваясь, производительные силы влекут новое разделение труда, что приводит к новой форме собственности. Интерес частной собственности при этом облекается в форму всеобщего интереса. Право возникает одновременно с частной собственностью в процессе разложения общины.

В очерке, рассматривающем историческое развитие как производное от промышленного, делается попытка дать общую схему восходящего исторического движения, базирующегося на преемственности форм орудийной деятельности, которые ломают национальные традиции. Но история частной собственности не может быть всемирной историей. Отчуждение приобретает вполне определенные формы эксплуатации пролетариата. Теоретические выводы нового материалистического понимания истории сформулированы в «Немецкой идеологии» особо: производительные силы общества достигают в своем развитии такой фазы, когда приносят бедствие. Класс, несущий на себе эти тяготы, является носителем революционного сознания. Условия, в которые поставлен этот класс, защищаются идеологией. Труд в будущем обществе должен быть распределен по-иному, характер деятельности изменен, всякое господство классов и сами классы уничтожены.

В период до «Немецкой идеологии» К. Маркс предпринимал усилия для определения предмета «обмирщенной» философии. В результате критическому анализу подверглась такая область гуманитарного знания, как право (1842 г.), историография (1843г.), политэкономия (1844 г.). Материалистическая реконструкция, социально-философская переориентация этих гуманитарных дисциплин означала предметное их сращение, как порожденных развитием форм частной собственности и коррелятивных им форм государства (форм идеологии). Все разделы гуманитарного знания были разделами одной науки - «политической теологии». Генетический анализ антиномий, ею порождаемых, привел Маркса к действительным противоречиям гражданского общества. 
2. Маркс К. К критике политической экономии. Предисловие // К. Маркс, Ф. Энгельс. Сочинения. Издание 2. - Т. 13. - М.: Политиздат, 1959. - С. 5-9.

3. Маркс К. Относительно взглядов Гегеля на соотношение между конкретно-историческими формами государства и абстрактной идеей государства. Из Крейцнахских тетрадей // К. Маркс, Ф. Энгельс Сочинения. Издание 2. - Т. 40. - М.: Политиздат, 1975. - С. 312.

4. Маркс К. Тезисы о Фейербахе // К. Маркс, Ф. Энгельс. Сочинения. Издание 2. - Т. 3. - М.: Политиздат, 1955. - С. 2-4.

5. Маркс К. Теорий прибавочной стоимости. // К. Маркс, Ф. Энгельс. Сочинения. Издание 2. - Т. 26, ч. 2. - М.: Политиздат, 1962. - С. 178.

6. Маркс К. Экономическо-философские рукописи 1844 г. // Маркс К., Энгельс Ф. Сочинения. Издание 2. - Т. 42. - М.: Политиздат, 1974. - С. 41-174.

7. Маркс К. Выписки из «0бщественного договора» Ж.-Ж. Руссо //Ж.-Ж. Руссо. Трактаты. - М., 1969. - С. 469-487.

8. Маркс К., Энгельс Ф. Немецкая идеология // Маркс К., Энгельс Ф. Сочинения. Издание 2. - Т. 3. - М.: Политиздат, 1955. - С. 7-544.
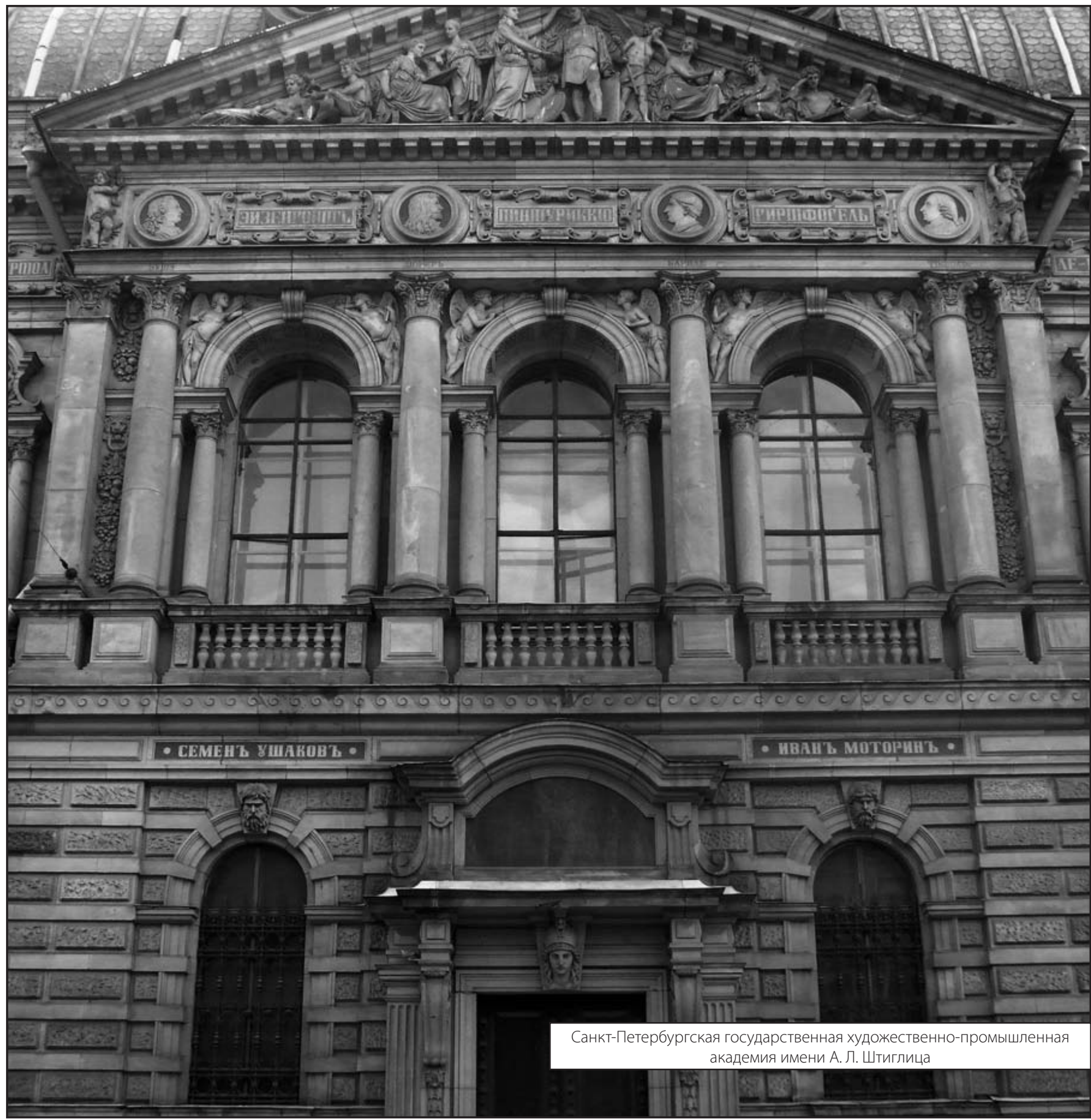